\title{
Remission of Anaphylactic Reaction to Alcohol
}

\author{
Jessica Rajan* and David Khan \\ University of Texas at Southwestern Medical Center, Dallas, Texas, USA
}

\begin{abstract}
There have been documented reports of anaphylaxis to beer and wine, however the etiology of those reactions is unclear. It is unclear whether ethanol, found in alcoholic beverages, or its metabolites acetaldehyde and acetic acid are responsible for this sensitivity.

Objective: We are reporting a patient who developed anaphylaxis to alcohol, which spontaneously remitted.

Methods: A patient with recurrent anaphylactic reactions (angioedema, hypotension, urticaria) to several types of alcoholic beverages was skin tested to ethanol and acetic acid. She then underwent oral challenge to ethanol and acetic acid on two different occasions separated by 6 months of abstinence from alcohol.

Results: Initial skin testing was positive only to acetic acid. On oral challenge, the patient developed urticaria and angioedema 5 minutes after drinking ethanol but not after consuming acetic acid. After six months of abstinence, the patient was again skin test positive to acetic acid but not to ethanol. She underwent a graded challenge to ethanol (6 steps from 1:1000 ethanol to $10 \mathrm{ml}$ of $1: 1$ at 15 minute intervals) during which she had no reaction. Two days later she consumed alcohol for the first time since the graded challenge and developed angioedema and hives. She again abstained from ethanol for 6 months, then rechallenged herself and had no reaction. She has since consumed ethanol for I year without reaction.
\end{abstract}

Conclusions: We conclude that anaphylactic reactions to alcohol may remit spontaneously. We recommend others to use caution with challenges involving multiple steps as it may cause inadvertent desensitization.

Hypersensitivity reactions to alcohol, including anaphylaxis are well documented, however it is unclear what component causes these reactions, considering alcoholic drinks are exceptionally complex. There have been speculations on sensitivities to grains, yeast, sulphite additives and histamine [1]. In prior reports it has been proposed that ethanol itself does not act as an allergen, but its metabolic products, acetaldehyde and acetic acid may act as haptens $[2,3]$. The natural history of these reactions is unknown. We report a case of documented anaphylaxis to alcohol with subsequent spontaneous remission.

A 27 year old female with history of allergic rhinitis and eczema presented to the allergy clinic with a history of pruritus, shortness of breath, facial swelling and hypotension after drinking wine, with similar but milder reaction to wine and margaritas in the past. Two and a half months prior, she reported "welps" after drinking a margarita, which resolved spontaneously after 30 minutes. Several weeks later she had a glass of white wine and developed similar rash along with pruritus and swelling of her lips and eyes. Three weeks later she drank $1 / 2$ glass of white wine and developed rash, shortness of breath, tongue swelling and went to the emergency room. She was found to be hypotensive with systolic blood pressure $60 \mathrm{mmHg}$ and required IV fluids. Based on her history, skin testing and oral challenge were performed to confirm the diagnosis of alcohol allergy. Skin prick tests were performed with white wine, margarita mix, tequila, ethanol $99 \%$ and acetic acid $99 \%$. All of these were negative except for acetic acid $99 \%$, which had a wheal of $10 \times 8 \mathrm{~mm}$ with a $30 \mathrm{~mm}$ flare after approximately 25 minutes. A control subject had a negative skin prick test to acetic acid. A single-blind oral challenge was also conducted and was negative in the following sequence: control-grape juice, $50 \mathrm{mls}$ of $2 \%$ acetic acid (diluted in grape juice), and $10 \mathrm{ml}$ of $99 \%$ ethanol (diluted in grape juice), all 30-60 minutes apart. Within five minutes of receiving $10 \mathrm{ml}$ of $99 \%$ ethanol masked in grape juice, she developed diffuse urticaria and facial angioedema without any change in blood pressure or respiratory complaints. She had rapid symptom resolution with epinephrine and antihistamines.
She was instructed to abstain from alcohol. Due to her desire to see if she could tolerate alcohol, she returned 6 months later for repeat skin testing and oral challenge.

Skin testing was repeated and was positive to acetic acid, at 1:10 dilution and undiluted concentrations. Due to her prior reaction to full dose challenge, we elected to perform a graded dose challenge. She underwent a single-blinded graded challenge with increasing doses of ethanol (diluted in grape juice) each 30 minutes apart: control-grape juice, $1 \mathrm{ml}$ 1:1000 ethanol, $1 \mathrm{ml}$ 1:100 ethanol, $1 \mathrm{ml} \mathrm{1:10}$

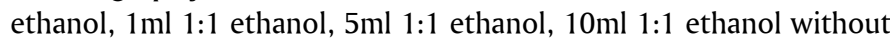
any adverse reaction after receiving a total of $16 \mathrm{ml}$ of pure ethanol. Two days later the patient consumed $1 / 2$ glass of wine and quickly developed facial angioedema and hives which responded rapidly to self-injectable epinephrine. She noted this reaction was milder than those previously. She was told to refrain from alcohol and return for another challenge.

She abstained from ethanol for 6 months and rechallenged herself, without our knowledge, without any reaction. Since then she has consumed ethanol for 1 year without reaction.

We present a case of anaphylaxis to alcohol, proven by oral challenge which spontaneously remitted. After abstaining from alcohol for 6 months, repeat skin test remained positive to acetic

*Corresponding author: Jessica Rajan, University of Texas at Southwestern Medical Center, Dallas, Texas, USA, E-mail: jessica.rajan@phhs.org

Received October 22, 2010; Accepted November 10, 2010; Published November 12,2010

Citation: Rajan J, Khan D (2010) Remission of Anaphylactic Reaction to Alcohol. J Aller Ther 1:104. doi:10.4172/2155-6121.1000104

Copyright: (C) 2010 Rajan J, et al. This is an open-access article distributed under the terms of the Creative Commons Attribution License, which permits unrestricted use, distribution, and reproduction in any medium, provided the original author and source are credited. 
acid but she had no reaction to oral graded challenge to ethanol. It is possible that during the repeat graded challenge, she was inadvertently desensitized to ethanol or had a false negative challenge. She then had another reaction 2 days post challenge/ desensitization.

It is unclear what component of alcoholic drinks may be responsible for an individuals sensitivity to them and the mechanism by which it would act. Ethanol itself has been shown to cause an increase in total serum IgE levels, although the mechanism is unclear [4]. Acetic acid has been proposed to cause type I hypersensitivity responses but its size makes it likely to be a hapten rather than an allergen [5].

In our case, the patient abstained from alcohol for 6 months and has since had no reaction. We propose that anaphylactic reactions to alcohol may remit spontaneously as in our patient. We would also recommend others to use caution with challenges involving multiple steps as it may cause inadvertent desensitization.

\section{References}

1. Vally H, Carr A, El-Saleh J, Thompson J (1999) Wine-induced asthma: a placebo-controlled assessment of its pathogenesis. J Allergy Clin Immuno 103:41-46

2. Schwarzenbach-Stöckli S, Bircher AJ (2007) Intolerance to alcohol in a patien sensitized to acetaldehyde and acetic acid. Allergologie 30: 139-141.

3. Vally H, Thompson PJ (2003) Allergic and asthmatic reactions to alcoholic drinks. Addict Biol 8: 3-11.

4. Gonzalez-Quintela A, Vidal C, Gude F (2004) Alcohol, IgE and allergy. Addict Biol 9: 195-204.

5. Boehncke WH. Gall H (1996) Ethanol metabolite acetic acid as causative agent for type-1 hypersensitivity-like reactions to alcoholic beverages. Clin Exp Allergy 26: 1089-1091. 